\title{
A study on strategic management of logistic enterprise from financial perspectives based on S.F. Express
}

\author{
Roujia Zhang ${ }^{1, a}$ \\ ${ }^{1}$ Business school, Shandong University Weihai, 180 Wenhua Xilu, Weihai 264209, China \\ aRoujiazh@163.com \\ ${ }^{*}$ Corresponding author: Roujia Zhang
}

\section{Keywords: Logistics Industry, S.F. Express, Strategic Management, Financial Ratios}

\begin{abstract}
This research will show the effectiveness of the strategic management of S.F. Express on the basis of its financial ratios and some strategic suggestions in its future operations. By studying the performance of S.F. Express, this research will examine the connection between strategic management and financial analysis.
\end{abstract}

\section{Introduction}

Financial management is of vital importance for a corporation, since it provides various information which reflects the performance of a company and directs an entity to make right choices. Through some financial ratios, we can measure the profitability, solvency of a company, doing the best investment. What's more, a company cannot stay stronger and longer without some strategic management. Since strategies are connected to all divisions of a company, keeping balance of the functions of different departments, it also helps a corporation to locate itself in the business background in order to take over its advantages, avoiding its weakness. In other words, these two perspectives can be combined together to make the wisest options for an enterprise.

In recent years, with the fast growing of the economy and the development of the infrastructure in China, there shows a rapid growth in logistics industry. It is reported that the scale of Chinese express delivery business has ranked first in the world for 4 consecutive years. With an average growth rate of $42 \%$ among last 10 years, the national express service reached 40.06 billion pieces in 2017 which is 32.4 times than that in 2007. And the revenue of express service was nearly 500 billion RMB in 2017 which is 14.5 times as many as that in 2007, while the annual growth rate has reached $30.6 \%$.[1] As a consequence, logistics companies appears to have a boosting development in these years which has aroused a fierce competition in this field. So, to survive in this competitive industry seems to be a huge problem for these companies. However, S.F. Express has successfully kept alive in this battle, becoming a leading delivery brand in China. The achievement made by S.F. Express can be considered an extremely amazing example of fantastic strategic management.

This research is aim to examine the effectiveness of the strategic management of a company based on its financial perspectives. Through some financial figures, we can understand the connection between strategic management and financial analysis.

\section{Literature Review}

\subsection{Introduction of logistics industry}

In a general business sense, logistics is a kind of management of the flow of the things between the point of origin and the point of consumption. Logistics industry includes the transportation of physical items, as well as some abstract stuff. In this research we mainly focus on the physical points which usually involves the integration of inventory, transportation, warehousing and so on.

Logistics service is an integration of a variety of delivery modes which organizes the sea transportation, land transportation, air transportation in a scientific and efficient way. Therefore, it can satisfy customers' needs by choosing the best transportation route, taking the shortest transportation time with the highest efficiency, lowest cost and safest way. So this system can make 
the best use of resources while protecting the environment.

Secondly, it breaks the boundary between production and transportation. Through the concept of supply chain, it has been integrated into the plan and control of the whole process of production and marketing that makes an optimal operation of an enterprise. It has realized the unity of logistics, capital and information on the basis of modern information technology. It also reduces the cost, making suppliers, vendors, distributors, logistics providers and consumers achieve a win-win strategy.

Thirdly, it emphasizes that the purpose of transportation is to serve customers and that to meet customer' requirements is the main task of transportation service. In order to achieve this goal, logistics providers have to develop some specialized and personalized projects.

Nowadays, there is a trend of combination of electronic commerce and logistics that due to the fast growing of technology. In particular, online shopping is quite popular in these years which pushes the development of logistic industry in China.

In recent years, although the growth rate of China's social logistics has slowed down, the steady growth of the economy has also pushed the rigid demand of the logistics industry. In 2016, the total amount of the logistics in the whole country was about 229 trillion RMB, showing an increase of $6.1 \%$ over the previous year.

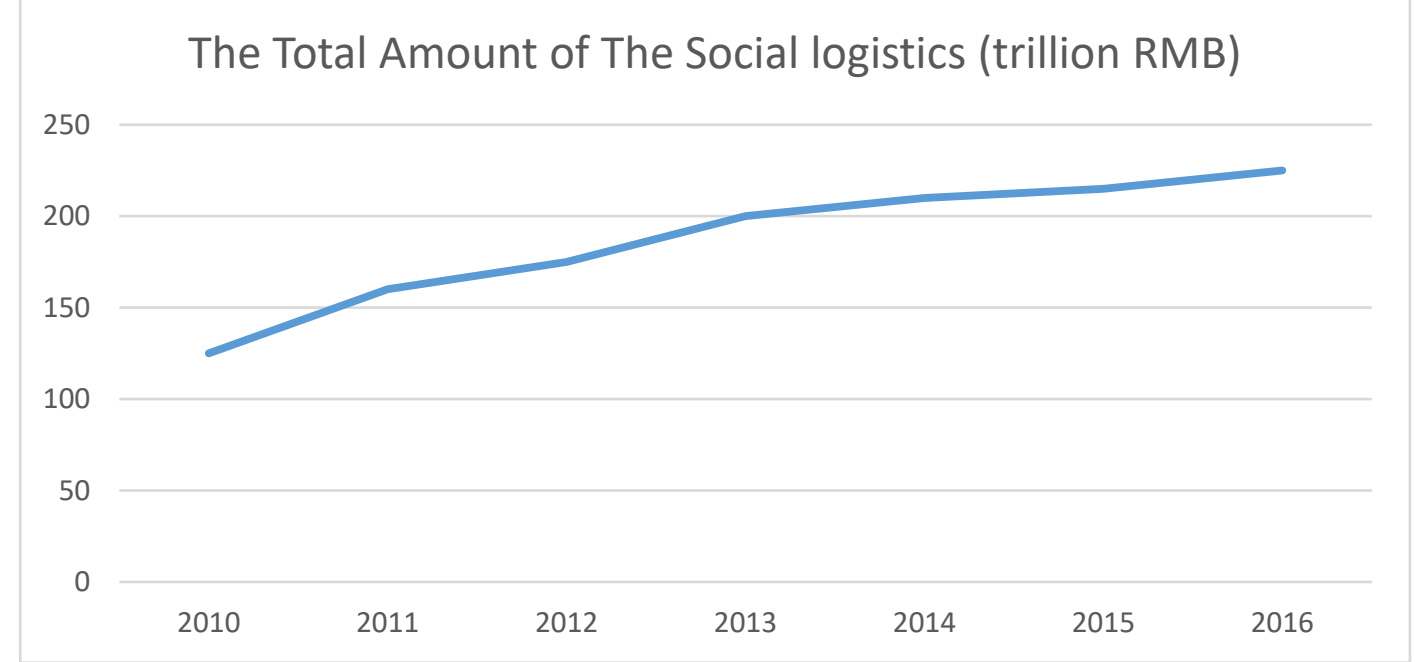

With the increase of the total amount of the social logistics, the total logistic cost which includes transportation cost, storage costs, management costs has maintained a growth trend. In 2016, the total cost of social logistics was 11 trillion and 100 billion RMB which showed an increase of $2.9 \%$ over the previous year. From 2010-2016, the annual growth rate of the total logistic cost in China reached $7.73 \%$, reflecting the expansion of the total cost of the logistic industry in China.[2]

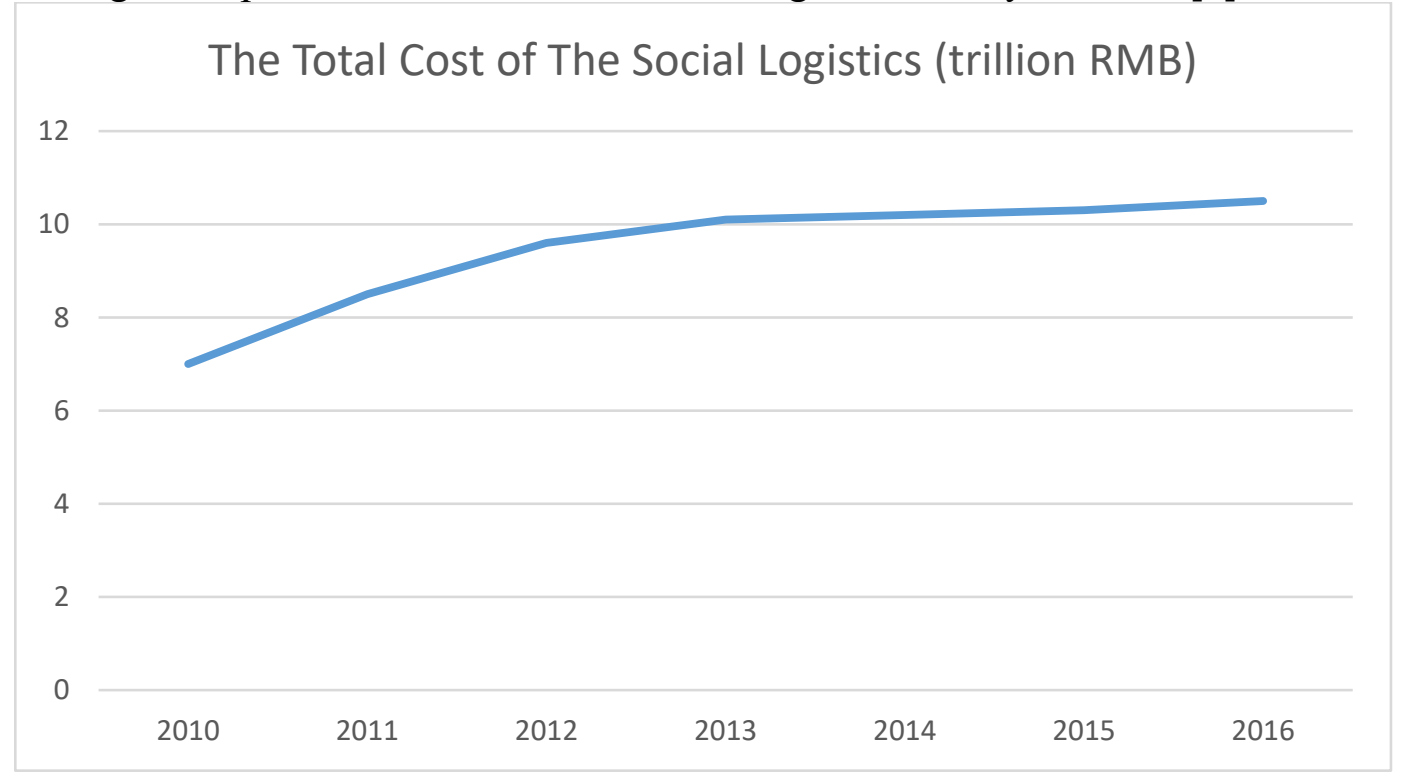




\subsection{Strategic instrument}

\subsubsection{Environment monitoring}

\section{(1) PEST model}

PEST analysis (P for political segment; E for economic segment; $\mathrm{S}$ for social segment; $\mathrm{T}$ for technological segment) is a simple and widely used model that describes a framework of macroenvironment factors used in the environment scanning component of strategic management. It is a part of external analysis and gives an overview of different kind of macro-environment factors to be taken into consideration, helping stakeholders make sense of market growth or decline, business position, potential and direction for operations. And then stakeholders can take advantage of the opportunities while avoiding their weakness.

In October 2014, in the medium and long term planning of the development of logistics industry (2014 - 2020), the State council pointed out the support for the construction of warehousing, distribution equipment, logistics information platforms, which were closely related to the construction and manufacturing enterprises. The council encouraged the construction of the public outer of warehousing and the introduction of third party logistics organizations as well. What is more, it gave huge support to the traditional transportation and storage enterprises so that they can extend their service to the upstream and downstream of the supply chain, build the third party supply chain management platforms and provide integrated services for the manufacturing sectors, such as procurement logistics, recycling logistics, supply chain financing and information tracing.[3]

In 2015, the NDRC issued the notice on accelerating the implementation of major modern logistics projects. The notifications pointed out that the implementation of the "medium and long term planning for the development of the logistics industry (2014-2020 years)" (National Development [2014]42) and the three - year action plan for the development of the logistics industry (2014-2016 years) were added so that important logistics infrastructure construction can be strengthened. It also aimed to lead the investment from the public to the logistics industry and improve the construction of the major modern logistics projects. Some specific performances are written below. By 2020, relying on the logistics infrastructure network covering the main logistics nodes in the country, advanced technology, convenient and efficient, green environmental protection and orderly construction will be basically established. The construction of modern transit transport facilities, including the port railway and the transport freight yard of the highway, collecting and distributing facilities, railway container central stations, container terminals for inland cities and ports will be improved. [4]

The construction of the Silk Road also gives great opportunities to the development of the logistics industry.

With the accelerated process of economic globalization, in order to improve the competitiveness of the market enterprises often need to put all the resources into the core business in order to seek the effectiveness and efficiency of the social division of labor and cooperation to maximize the efficiency. The result of specialized division of labor leads to the separation of many non - core businesses from the production and operation of enterprises. The cost of logistics is greatly influenced by the scale of economy. It often needs to invest high capital, manpower and material resources to achieve a certain scale economy, which is a huge burden for enterprises. Therefore, in the case of specialized division of labor, enterprises often choose to outsource logistics first. In recent years, with the need of market competition, more and more manufacturing enterprises, especially the manufacturing enterprises with global purchasing and sales demand, outsource their logistics business to the professional logistics enterprises and bring greater development space to the cross-border logistics industry.

The development of information technology has created conditions for enterprises to build efficient systems. Advanced information technology realizes the rapid and accurate transmission of data. On the one hand, it improves the automation level of logistics service providers' warehousing management, loading and unloading transportation, purchasing, ordering, distribution and shipping, order processing, and promotes the integration of order, storage and transportation. At the same time, the powerful network system enables third party logistics providers to communicate with other professional service providers more quickly, integrating into customer management process, meeting 
the users' demand for tracking and query in time and conveniently and improve the ability of logistics service providers to control the quality of logistics services, raising the efficiency of logistics services. The development of modern information technology has expanded the development space of modern logistics service. It is one of the key factors for the logistics enterprises to reduce the operating cost, improving the service quality and strengthening the management of the enterprises.

(2) Competitive environment

To understand the competition of a business, this research uses Porter's Five Forces model[5]. Porter's five forces include three forces from 'horizontal' competition - the threat of substitute products or services, the threat of competitive rivalry, and the threat of new entrants, and two other from 'vertical' competition - the bargaining power of suppliers and the bargaining power of customers.

In terms of the threat of new entrants, it is determined by the profitability of an industry. Usually, profitable industries that yield high returns will attract new firms. New entrants eventually will decrease the profitability for other firms in the industry. And the threat of substitutes comes when a substitute product uses different technology or material to try to solve the same economic need.

The bargaining power of customers is described of the ability of customers to put the firm under pressure, which also affects the customers' sensitivity to price changes.

The bargaining power of suppliers is also described as the market of inputs. Suppliers of raw material, labor, and services to the firm can be a source of power over it when there are few substitutes.[6]

There are many participants in the logistics industry. The industry concentration degree is low, the degree of marketization is high, and the competition is large. According to the competitive characteristics of the current logistics industry in China, there are three main types of competitors in the current industry: the first category is large state-owned logistics enterprises; the second is the large logistics enterprises abroad; the third category is the private logistics enterprises. With China's entry into the world economic system, the government has fully opened the control of international logistics companies into China, and international logistics companies have entered the Chinese market in succession. These companies, with their strong financial strength and rich experience in industry, have certain advantages in competing for cross-border logistics business of multinational companies. In contrast, the management mode of domestic logistics enterprises is relatively backward, and the lack of core competitiveness will make the competition of the logistics industry aggravate and the international competitiveness to a certain extent.

In addition, customers have numerous choices that also puts great pressure on the logistics companies. In order to gain more market share, companies may choose to cut down their prices. In this case, it gives customers more power to bargain.

\subsubsection{Financial ratio analysis}

(1) Short-term solvency ratio

From the liquidity aspect, this article focus on the current ratio.

Current ratio $=$ Current Asset $/$ Current Liabilities

The current ratio, an indication of liquidity, measures whether or not a firm has enough resources to meet its short - term obligations. [7]It compares a firm's current assets and its current liabilities. In many cases, we would consider a high current ratio to be better than a low current ratio, because a higher figure indicates that the company is more likely to pay back its debt. However, large current ratios are not always a good sign for investors. If they are too high, we may have concern about that the company have poor efficiency of using its short - term financing facilities. [8]

(2) Long-term solvency measure

From this perspective, this article mainly focus on the long term debt-equity ratio and the interest coverage ratio.

Long term debt-equity ratio $=$ Long-term debt / Equity

Interest coverage ratio $=\mathrm{EBIT} /$ Interest

The long term debt-equity ratio also kwon as risk gearing, indicates the relative proportion of shareholder' equity and debt used to finance a company's asset. 
The interest coverage ratio shows the ability of a business to make interest payments. This ratio would normally range from 1.5 to 2.0 . If the ratio is less than 1 , it means that the earnings available is not sufficient to cover the interest expense, suggesting that the firm may have a problem with its solvency.

(3) Asset utilization ratio

In terms of this financial figure, this article use inventory turnover, receivables turnover and asset turnover to make further understanding of this ratio.

Inventory turnover $=$ Cost of goods sale / Inventory

Receivable turnover $=$ Sales $/$ Accounts receivable

Asset turnover $=$ Sales revenue $/$ Total asset

The inventory turnover is a measure of the number of times which inventory is sold or used in a particular time. It is calculated to check out whether a company has an excessive inventory in comparison to its sales level.

The receivable turnover is calculated to see the effectiveness of a firm in extending credit as well as colleting debt. Usually, a high ratio may suggest that the company's extension of credit and collection of accounts receivables is efficient. While a low ratio implies the company is not making the timely collection of credit.

The asset turnover measures the efficiency of a company's use of its assets in generating sales revenue to the company.

(4) Profitability ratio

This article uses the profit margin, return on assets (ROA), return on equity(ROE) to measure the profitability of a company.

Profit margin $=$ Net income $/$ Sales

Return on assets $(\mathrm{ROA})=$ Net income $/$ Total assets

Return on equity $(\mathrm{ROE})=$ Net income $/$ Total equity

The connection of this three margin will discuss in the analysis of DuPont Model.

(5) Market value ratio

This research will use PE ratio to measure the market value of the company.

Price-earnings ratio $=$ Price per share $/$ Earnings per share

The PE ratio depends on the market's perception of the risk and future growth in earnings. A company with a low PE indicates that the market perceives it as higher risk or lower growth.

\subsection{DuPont Model}

DuPont Model can be considered to be a better and deeper understanding of ROE (Return on Equity) which breaks down ROE into three distinct elements. This analysis enables the analyst to comprehend the source of superior (or inferior) return by comparison with companies in similar industries.

The equation below is the basic formula of DuPont identity.[9]

$\mathrm{ROE}=($ Profit margin $) *($ Asset turnover $) *$ (Equity multiplier $)$

$=($ Net income $/$ Revenue $) *($ Revenue $/$ Average Total Asset $) *$ (Average

Total Asset/Average Total Equity)

$=$ Asset turnover $*$ Profit margin

This research will breaks down the asset turnover and profit margin into much

Further parts in order to have a comprehensive understanding of S.F. Express. 


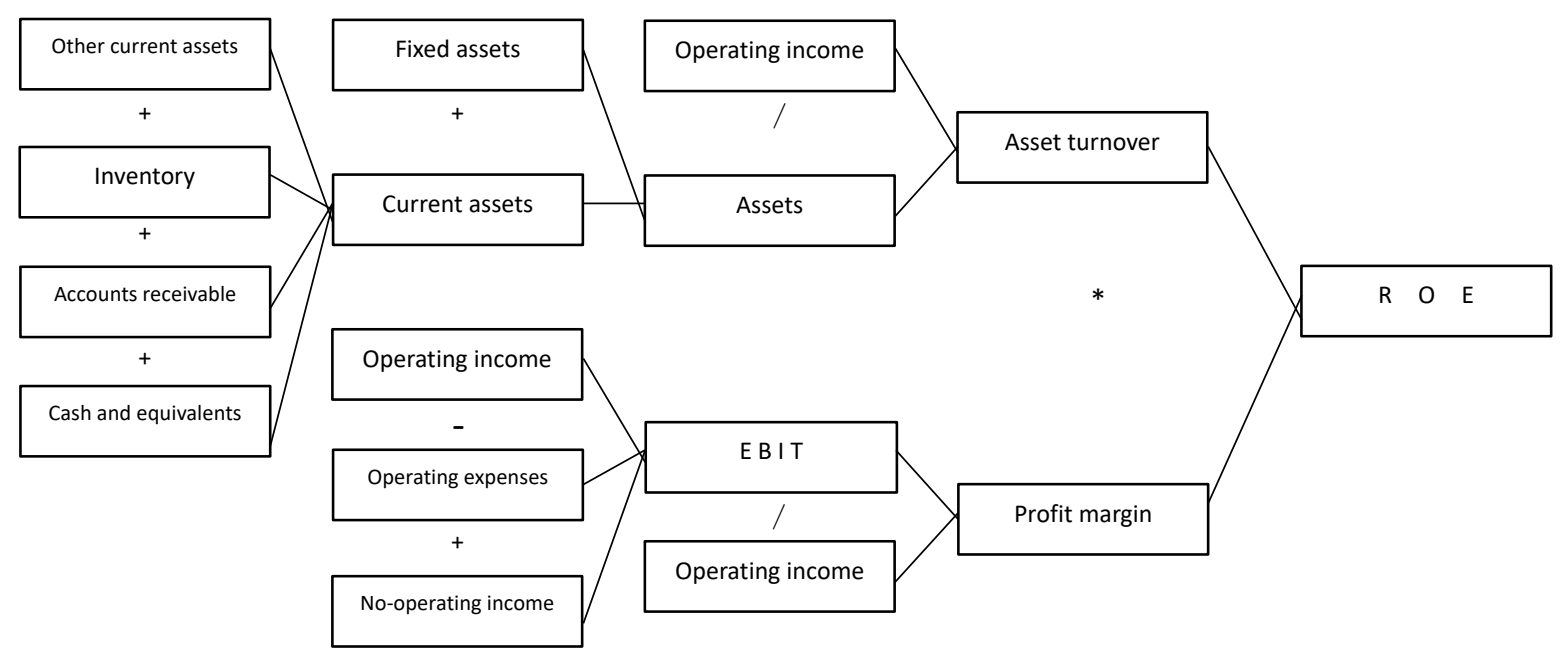

Fig 1.Diagram of DuPont analysis[10]

\section{Methodology}

S.F. Express is an express company mainly engaged in international and domestic delivery business. It was founded in Guangdong China in 1993. In addition, S.F. Express is one of the fastest delivery company in China's express delivery industry. With the mission of "satisfying the customers, promoting the economy and developing the national express delivery industry", S.F. Express has actively explored the customer's needs, constantly launched new service project, and provided the customers with a fast and safe transportation channel.

This research is developed on the basis of S.F. Express 2017 annual reports, compared with the 2016 annual reports. All annual reports are from the official website of S.F. Express.

\section{Finding and Result}

We can draw some conclusions via the financial analysis. S.F. Express has a promising future as the positive development of the express delivery. Also this company has made some strategic changes in the personnel, its technology support and so on in order to catch up the needs of its further development.

\subsection{Operating income and Gross profit margin}

The operating income and gross profit margin in 2017 has increased by $23.68 \%$ and $2.66 \%$. Among the revenue, express delivery is about $99.32 \%$ which contributed a lot to the revenue, showing an increase of $23.57 \%$. Meanwhile the revenue of the logistics industry also shows a growing trend. It means that the main business of S.F. Express has a positive future and also express delivery will always be the main direction in the long run that S.F. Express is supposed to focus on.

\subsection{Expenses}

Among all the expenses, I picked up the selling expenses and the administrative expenses that have a significant influence on the strategic management of S.F. Express.

When it comes to the selling expenses, the expenses have an increase of $17.96 \%$ that primarily caused by the increase of the outsource of the information technology services and marketing expenses as well. However, there is a decline of the labor cost that may offset the increase in the selling expenses.

Firstly, the expenses related to the information technology service has risen by $50.16 \%$. The reason why there is such a dramatic increase is that S.F. Express rely heavily on the information and technology. The I.T. service is a core part of transportation which accelerate the speed and improve the efficiency of the delivery process. Thus, to utilize this point, specialization of I.T. services seems 
to be fairly necessary. As a consequence, the company spent more money on outsourcing of I.T. services.

Secondly, the marketing expenses rose sharply during 2017. For the purpose of promotion, it is a really common measure taken by S.F. Express.

Thirdly, the labor cost has decreased by $4.92 \%$ because of the strategy change in the workforce. From the annual report in 2017 and 2016, it shows that the company hired less workers who has poor education, which indicates that it has reduced the number of staff of the operating level.

In respect of the administrative expenses, there shows a $20.90 \%$ increase in this expenses. And I also consider the increase in the labor cost as the primary cause which went up by $18.84 \%$ during 2017. We can infer that the company has recruited more staff of the strategic level on account of the increasing number of well-educated workers.

\section{Discussion}

By analyzing the financial figures of E.F. Express, it performed well these years, suggesting a promise future of the company. It also provides a good example of the management of its external service in addition to its internal business.

Referring to the development experience of western countries, in the future, China's express industry will gradually form a few large-scale express enterprises as the leading, many small and medium-sized express enterprises as a regional complement to the competition pattern. So in order to keep its leading position in the express market, S.F. Express is supposed to maintain and increase its market share. In terms of the domestic market, on the one hand, S.F. Express should maintain its long-term cooperation with some big name companies, forming a strategic partnership with them. On the other hand, it can reconsider its price strategy and cost strategy, cutting down its cost and reducing its market price. Meanwhile, S.F. Express should continue to expand its overseas business, making good use of the on belt on road policy.

With the trend of intelligent logistics, S.F. Express should gradually push the enterprise to transform from labor-intensive to technology intensive industry. In the future, the company should continue to increase the investment of new generation computer technology such as automated logistics equipment, big data, cloud computing, new generation intelligent interactive equipment and unmanned aerial vehicles, advancing the layout of forward-looking logistics information technology, maintaining the company's forward-looking in the field of information technology and enhancing the enterprise's thinking of logistics system and the ability of dimension, perception, learning, analysis, decision-making and intelligent construction.

In the aim of developing a sound social reputation. S.F. Express should adhere to green logistics policy, using green packaging and new energy vehicles. Concerning about the green packaging, it should be committed to the research and innovation of green packaging products. At the same time, recyclable packaging boxes should be developed to prolong the life cycle of packaging products. The company also need to reduce the cost of reproduction. In the aspect of new energy vehicles, combined with national policies and the actual needs of enterprise, the plan of new energy logistics vehicles should be applied to the real operation step by step.

S.F. Express should not only need to pay attention to the basic operation, but also focus on the quality of its labor force. To keep a low return over rate, it should constantly improve the welfare of its employees. In this way, the company can attract more high-quality and advanced workers as well, strengthening its work force and improving its internal efficiency.

\section{Conclusion}

Through the analysis of S.F. Express, it shows a satisfying result of its financial figures, indicating its successful strategic management.

The case of E.F. Express is a typical example which shows the close relationship between strategic management and the financial figures. Proper managing actions can lead to better performance. While financial ratios provide helpful measures to test the effects of the strategic management of an 
enterprise.

\section{References}

[1] Analysis of the current situation and development trend of China's logistics industry in 2017, CNII. Retrieved 2017-12-28

[2] Analysis of the current situation and development trend of China's logistics industry in 2017, CNII. Retrieved 2017-12-28.

[3] State council of China, the medium and long term (2014 to 2020) plan of the Development of logistics industry. Retrieved 2014-10-4.

[4] NDRC, Circular on speeding up the implementation of major projects in modern logistics. Retrieved 2015-8-13.

[5] Michael E. Porter, "How Competitive Forces Shape Strategy," May 1979 (Vol. 59, No. 2), pp. 137-145.

[6] Porter's five forces analysis, Wikipedia. Retrieved 2018-7-9.

[7] Current ratio, Wikipedia. Retrieved 2018-7-22.

[8] "Current Ratio | Formula | Example | Analysis | Industry Standards". accounting-simplified.com. Retrieved 2016-10-11.

[9] Phillips, Matt (9 December 2015). "The DuPont invention that changed how things work in the corporate world". Quartz (publication). Retrieved 9 December 2015.

[10] DuPont analysis, Wikipedia. Retrieved 2018-4-19. 